\title{
John Frow
}

\section{The Last Things Before the Last: Notes on White Noise}

The edges of the earth trembled in a darkish haze. Upon it lay the sun, going down like a ship in a burning sea. Another postmodern sunset, rich in romantic imagery. Why try to describe it? It's enough to say that everything in our field of vision seemed to exist in order to gather the light of this event.

—Don DeLillo, White Noise

$\mathbf{G}_{\text {ötterdämmerung. Why try to describe it? }}$ It's been written already, by Conrad, among others. Postmodern writing always comes after, the postmodern sunset is another sunset, an event within a series, never an originating moment but mass-produced as much by the cosmological system as by the system of writing. But the word postmodern here means more than this: this passage from White Noise refers back to an earlier one about the effects of an industrial (or postindustrial) disaster:

The South Atlantic Quarterly 89:2, Spring 1990 Copyright (C) I990 by Duke University Press. CCC $0038-2876 / 90 / \$ 1.50$ 
Ever since the airborne toxic event, the sunsets had become almost unbearably beautiful. Not that there was a measurable connection. If the special character of Nyodene Derivative (added to the everyday drift of effluents, pollutants, contaminants and deliriants) had caused this aesthetic leap from already brilliant sunsets to broad towering ruddled visionary skyscapes, tinged with dread, no one had been able to prove it.

The conditional clause structure and the repeated negation convey a pessimistic sense of undecidability, but it seems clear that industrial poison is a crucial component of the postmodern aesthetic, "rich in romantic imagery"- and vice versa. We could as well say "another poisonous sunset," or speak of an "airborne aesthetic event." It is not that the postmodern marks the return of aestheticism, a nonironic deployment of the full romantic cliché, but rather that it is the site of conjunction of the beautiful and the toxic, of Turner's Fire at Sea (1835), his "broad towering ruddled visionary skyscapes" and our postindustrial waste. This is thus, in Lyotard's sense, an aesthetic of the sublime: "With the sublime, the question of death enters the aesthetic question." It involves terror (the skyscapes are "tinged with dread") and ineffability, "the unpresentable in presentation itself." Why try to describe it? The twist here is that the sense of the inadequacy of representation comes not because of the transcendental or uncanny nature of the object but because of the multiplicity of prior representations. Priority of writing, priority of television, priority of the chain of metaphors in which the object is constructed. "We stood there watching a surge of florid light, like a heart pumping in a documentary on color TV."

Nor is there a lack of irony so much as a kind of self-effacement before the power of the stories which have gone before. The DeLillo passage I quoted at the beginning continues: "Not that this was one of the stronger sunsets. There had been more dynamic colors, a deeper sense of narrative sweep." Far from declining, the great nineteenthcentury narratives continue to infuse the world with meaning, with a meaningfulness so total that the only possible response is ambivalence. The skies of this belated world are "under a spell, powerful and storied." They take on 
content, feeling, an exalted narrative life. The bands of color reach so high, seem at times to separate into their constituent parts. There are turreted skies, light storms, softly falling streamers. It is hard to know how we should feel about this. Some people are scared by the sunsets, some determined to be elated, but most of us don't know how to feel, are ready to go either way.

Malign and beautiful, interpretable not so much to infinity as within an endless loop between two contradictory poles, this labile postmodern object causes "awe, it is all awe, it transcends previous categories of awe, but we don't know whether we are watching in wonder or dread." Singular but recurrent, an event (a change, a deviation, a production of newness) within the serial reproduction of sameness, it announces (but how typically modernist a gesture) nothing but its own gesture of annunciation: "There was nothing to do but wait for the next sunset, when the sky would ring like bronze."

In a town there are houses, plants in bay windows. People notice dying better. The dead have faces, automobiles. If you don't know a name, you know a street name, a dog's name. "He drove an orange Mazda." You know a couple of useless things about a person that become major facts of identification and cosmic placement when he dies suddenly, after a short illness, in his own bed, with a comforter and matching pillows, on a rainy Wednesday afternoon, feverish, a little congested in the sinuses and chest, thinking about his dry cleaning.

White Noise is obsessed with one of the classical aims of the realist novel: the construction of typicality. What this used to mean was a continuous process of extrapolation from the particular to the general, a process rooted in the existence of broad social taxonomies, general structures of human and historical destiny. Social typicality precedes the literary type-which is to say that the type is laid down in the social world; it is prior to and has a different kind of reality from secondary representations of it. First there is life, and then 
there is art. In White Noise, however, it's the other way round: social taxonomies are a function not of historical necessity but of style. Consider this description of the parents of Jack Gladney's students:

The conscientious suntans. The well-made faces and wry looks. They feel a sense of renewal, of communal recognition. The women crisp and alert, in diet trim, knowing people's names. Their husbands content to measure out the time, distant but ungrudging, accomplished in parenthood, something about them suggesting massive insurance coverage.

This type is not a naive given, an embodied universality, but a selfconscious enactment; the middle-class parents know the ideality they are supposed to represent, and are deliberately living up to it. But this means that the type loses its purity, since it can always be imitated, feigned; or rather that there is no longer a difference in kind between the social category and the life-style which brings it into everyday being: the type ceaselessly imitates itself-through the ritual assembly of station wagons, for example, which "tells the parents they are a collection of the like-minded and the spiritually akin, a people, a nation."

It is thus no longer possible to distinguish meaningfully between a generality embedded in life and a generality embedded in representations of life. The communal recognition that constitutes the social class is part of a more diffuse system of recognitions conveyed through an infinitely detailed network of mediations. When Jack tries to characterize the convicted murderer his son Heinrich plays chess with, he draws on a range of mass-cultural information, like those psychological "profiles" that construct, above all for television, a tax. onomy of criminal types: "Did he care for his weapons obsessively? Did he have an arsenal stacked in his shabby little room off a six. story concrete car park?" A computer operator "had a skinny neck and jug-handle ears to go with his starved skull-the innocent prewar look of a rural murderer." Those who would be affected by the air borne toxic event would be "people who live in mobile homes out in the scrubby parts of the county, where the fish hatcheries are." The type of the bigot, embodied in Murray Siskind's landlord, is "very good with all those little tools and fixtures that people in cities never 
know the names of," and tends to drive a panel truck "with an extension ladder on the roof and some kind of plastic charm dangling from the rearview mirror." The whole of this world is covered by a fine grid of typifications, so detailed and precise that it preempts and contains contingency.

If the type is susceptible to minute description, then the traditional novelistic tension between detail and generality falls away, and Lukács's account of typicality becomes unworkable. For Lukács, typicality is best embodied in the category of particularity (Besonderheit), which stands midway between philosophical generality (Allgemeinheit) and descriptive detail, or singularity (Einzelheit); in a postmodern economy of mediations, however, where representations of generality suffuse every pore of the world, the opposition between the general and the singular collapses as they merge into a single, undialectical unity. The petit fait vrai of the realist novel, the meaningless detail whose sole function is to establish a realism effect, is no longer meaningless. Reconstructing the scene of his wife's adultery, Jack mentions objects like "the fire-retardant carpet" and "the rental car keys on the dresser"; the definite article here marks these-as it does in much of Auden's poetry-not as concrete particulars but as generic indicators; they are not pieces of detail broken off from the contingent real but fragments of a mundane typicality.

The complexity and intricacy of the type-whether it is a character, a scene, or a landscape-is made possible by the constant repetition of its features: it is reproduced as a sort of amalgam of television and experience, the two now theoretically inseparable. At its simplest, this inseparability gives us something like the image of the grandparents who "share the Trimline phone, beamish old folks in hand-knit sweaters on fixed incomes." This is of course a joke about typicality, or rather about its construction in Hollywood movies and television advertising. A somewhat more complex play with typification is this:

A woman in a yellow slicker held up traffic to let some children cross. I pictured her in a soup commercial taking off her oilskin hat as she entered the cheerful kitchen where her husband stood over a pot of smoky lobster bisque, a smallish man with six weeks to live. 
This description depends on the reader's recognition of the particular soup commercial, or at least the genre of commercials, that is being parodied by role reversal, and by the substitution of the traffic warden's yellow raincoat for the traditional and stereotyped fisherman's yellow raincoat - a substitution of the urban and feminine for the premodern world of masculine work. But part of the effect of this passage, as of that quoted at the beginning of this section, lies in its stylistic trick of pinning down the type (welcoming spouse at hearth) to an absurdly particular detail. What most of these typifications have in common, however, is their source in a chain of prior representations. Jack's dying, for example, is projected through a characterology taken from the movies, as in Murray's line to him that people "will depend on you to be brave. What people look for in a dying friend is a stubborn kind of gravel-voiced nobility, a refusal to give in, with moments of indomitable humor." The cliché is a simulacrum, an ideal form that shapes and constrains both life and death.

Let us say that this new mode of typicality has two features: it is constructed in representations which are then lived as real; and it is so detailed that it is not opposed to the particular. The name usually given to it in the genre of postmodernity is the simulacrum. Here are some notes:

(I) Early in White Noise Jack and Murray visit the most photographed barn in America. They pass five signs advertising it before reaching the site, and when they arrive there find forty cars and a tour bus in the car park, and a number of people taking pictures. Murray delivers a commentary: "No one sees the barn," he says. "Once you've seen the signs about the barn, it becomes impossible to see the barn. . . . We're not here to capture an image, we're here to maintain one. Every photograph reinforces the aura. . . . We've agreed to be part of a collective perception. This literally colors our vision. A religious experience in a way, like all tourism. . . They are taking pictures of taking pictures.... What was the barn like before it was photographed? . . What did it look like, how was it dif ferent from other barns, how was it similar to other barns? We can't answer these questions because we've read the signs, seen the people 
snapping the pictures. We can't get outside the aura. We're part of the aura. We're here, we're now." To this should be added another comment: "Murray says it's possible to be homesick for a place even when you are there."

(2) At the center of Walter Benjamin's argument about the mechanical reproduction of representations was the thesis that it would have the effect-the liberatory effect-of destroying the quasireligious aura surrounding the work of art. It is clear that the opposite has happened: that the commodification of culture has worked to preserve the myth of origins and of authenticity.

(3) In the main street of DeLillo's Iron City is "a tall old Moorish movie theater, now remarkably a mosque"; it is flanked by "blank structures called the Terminal Building, the Packer Building, the Commerce Building. How close this was to a classic photography of regret."

(4) The evacuation of Jack and his family is conducted by an organization called SIMUVAC, which is "short for simulated evacuation. A new state program they're still battling for funds for." When Jack points out to one of its employees that this is not a simulated but a real evacuation, he replies: "We thought we could use it as a model"; it gives them "a chance to use the real event in order to rehearse the simulation."

(5) For Plato, the simulacrum is the copy of a copy. Violating an ethics of imitation, its untruth is defined by its distance from the original and by its exposure of the scandal that an imitation can in its turn function as a reality to be copied (and so on endlessly).

The most influential contemporary account of the simulacrum and the chain of simulations is that of Baudrillard. His is a melancholy vision of the emptying out of meaning (that is, of originals, of stable referents) from a world which is henceforth made up of closed and self-referring systems of semiotic exchange. In a state of what he calls hyperreality the real becomes indefinitely reproducible, an effect, merely, of the codes which continue to generate it. From the very beginning Baudrillard has been hostile to the scandalous opacity of systems of mediation. His is a historical vision: there was a referent; it has been lost; and this loss, as in Plato, is the equivalent of a moral fall.

By contrast, the account that Deleuze gives of the simulacrum in 
Différence et répétition, while retaining the formal structure of the Platonic model, cuts it off from its ties to a lost original, and cuts it off, too, from all its Baudrillardian melancholy. The world we inhabit is one in which identity is simulated in the play of difference and repetition, but this simulation carries no sense of loss. Instead, freeing ourselves of the Platonic ontology means denying the priority of an original over the copy, of a model over the image. It means glorifying the reign of simulacra, and affirming that any original is itself already a copy, divided in its very origin. According to Deleuze, the simulacrum "is that system in which the different is related to the different through difference itself."

(6) The most horrifying fact about the evacuation is that it isn't even reported on network television. "Does this thing happen so often that nobody cares anymore?" asks one man. "Do they think this is just television?"

(7) The smoke from the chemical spill is initially called a "feathery plume," then a "black billowing cloud," and finally an "airborne toxic event." Steffie and Denise, Jack's daughters, keep experiencing the symptoms described in the bulletin preceding the current one. One of these symptoms is déjà vu, and Jack wonders, "Is it possible to have a false perception of an illusion? Is there a true déjà $v u$ and a false déjà vu?" Later his wife Babette has a déjà vu experience of déjà vu.

(8) "The phone rang and I picked it up. A woman's voice delivered a high-performance hello. It said it was computer-generated, part of a marketing survey aimed at determining current levels of consumer desire. It said it would ask a series of questions, pausing after each to give me a chance to reply." Steffie, answering its questions, reads the label on her sweater: "virgin acrylic."

(9) Peter Wollen writes that in "an age marked by an ever-increasing and ever-accelerating proliferation of signs, of all types, the immediate environment becomes itself increasingly dominated by signs, rather than natural objects or events. The realm of signs becomes not simply a 'second nature' but a primary 'reality.' (The quotes around 'reality' mark the effacement of the traditional distinction between reality and representation in a world dominated by representations. )"

( Io) Lighted by helicopters, the airborne toxic event moves like an operatic death ship across the landscape: "In its tremendous size, it 
dark and bulky menace, its escorting aircraft, the cloud resembled a national promotion for death, a multimillion-dollar campaign backed by radio spots, heavy print and billboard, TV saturation."

The world of White Noise is a world of primary representations which neither precede nor follow the real but are themselves real-although it is true that they always have the appearance both of preceding another reality (as a model to be followed) and of following it (as copy). But this appearance must itself be taken seriously.

Consider these two passages about an adult looking at sleeping children: "I looked for a blanket to adjust, a toy to remove from a child's warm grasp, feeling I'd wandered into a TV moment." And "[ $\mathrm{t}]$ hese sleeping children were like figures in an ad for the Rosicrucians, drawing a powerful beam of light from somewhere off the page." Both moments are mediated by another moment, a memory or a metaphor which shapes them, endows them with a certain structure; this structure is a part of their reality. It is quite possible to distinguish one reality (the sleeping children) from another (the TV moment, the ad for the Rosicrucians), just as we can in principle distinguish literal from metaphorical language; it is possible for the novel to be ironical about the gap between these two realities. But this distinguishing and this irony are insecure. Real moments and TV moments interpenetrate each other-and it is, in any case, another (novelistic) representation which offers us this reality and this distinction. The world is so saturated with representations that it becomes increasingly difficult to separate primary actions from imitations of actions.

Indeed, it seems that it is only within the realm of representation that it is possible to postulate a realm of primary actions which would be quite distinct from representation. During the evacuation Jack notices groups of refugees:

Out in the open, keeping their children near, carrying what they could, they seemed to be part of some ancient destiny, connected in doom and pain to a whole history of people trekking across wasted landscapes. There was an epic quality about them that 
made me wonder for the first time at the scope of our predicament.

What he is seeing is of course a movie; and it is precisely because it is cinematic, because of its "epic quality," that the scene is real and serious to him. "Epic” here perhaps means something like "naive," lacking self-consciousness, and above all lacking any awareness of the cinematic nature of the experience. This paradox is even clearer in the case of Jack's fantasy about the death of Attila the Hun: "I want to believe he lay in his tent, wrapped in animal skins, as in some internationally financed movie epic, and said brave cruel things to his aides and retainers." The image is again of a heroic lack of self-consciousness, a naive immediacy to life and death:

No weakening of the spirit. No sense of the irony of human existence. . . . He accepted death as an experience that flows naturally from life, a wild ride through the forest, as would befit someone known as the Scourge of God. This is how it ended for him, with his attendants cutting off their hair and disfiguring their own faces in barbarian tribute, as the camera pulls back out of the tent and pans across the night sky of the fifth century A.D., clear and uncontaminated, bright-banded with shimmering worlds.

It is only in the movies, only through cultural mediation, that a vision of nonmediation is possible - and therefore absurd.

The central mediating agency in this world is television; indeed. for "most people there are only two places in the world. Where they live and their TV set. If a thing happens on television, we have every right to find it fascinating, whatever it is." The major statement is a speech made by Murray. He tells his students that

they're already too old to figure importantly in the making of society. Minute by minute they're beginning to diverge from each other. "Even as we sit here," I tell them, “you are spinning out from the core, becoming less recognizable as a group, less tar getable by advertisers and mass-producers of culture. Kids are ، true universal. But you're well beyond that, already beginning to drift, to feel estranged from the products you consume. Who are 
they designed for? What is your place in the marketing scheme? Once you're out of school, it is only a matter of time before you experience the vast loneliness and dissatisfaction of consumers who have lost their group identity."

The assumptions are astounding: we know that human worth can't be measured in terms of our relation to consumption - to money and commodities-and that the order of things transcends "the marketing scheme." But all that Murray is doing is stating the central, the deadly serious principles of a capitalist society. This is really how it is, the marketing scheme really does work, for most purposes, in a capitalist society, as the scheme of things; the whole social organization is geared to this equation. The propositions are monstrous, but only because we find it so hard to believe in the true and central awfulness of capitalism.

Television comes into this because of its crucial role in marketing - and this is to say that its importance lies not in the sheer quantity of representations that it generates, nor even in their content as messages, but in the fact that they are always directly linked to commodity production and the generation of profits, and that in order to serve these ends they work as an integral part of a system for the shaping and reshaping of human identity. Murray's students are thus "beginning to feel they ought to turn against the medium, exactly as an earlier generation turned against their parents and their country." When he tells them that "they have to learn to look as children again. Root out content. Find codes and messages," they reply that television "is just another name for junk mail."

But cultural criticism - the moralistic critique of the mass media that has been the stock in trade of liberal journalism-is of course not an option, certainly not for this novel, which is much more interested, in its own ironic but unconditional way, in, for example, Murray's quasi-mystical experience of television. It is, he says, "a primal force in the American home. Sealed-off, self-contained, selfreferring." Television

offers incredible amounts of psychic data. It opens ancient memories of world birth, it welcomes us into the grid, the network of little buzzing dots that make up the picture pattern. There 
is light, there is sound. I ask my students, "What more do you want?" Look at the wealth of data concealed in the grid, in the bright packaging, the jingles, the slice-of-life commercials, the products hurtling out of darkness, the coded messages and endless repetitions, like chants, like mantras. "Coke is it, Coke is it, Coke is it." The medium practically overflows with sacred formulas if we can remember how to respond innocently and get past our irritation, weariness and disgust.

A whole aesthetic is elaborated here, although unfortunately it's made up of the dregs of other aesthetic systems. Murray has the quixotic ability to disregard the banal surface of television and, with all the innocence of a formalist semiotician, to discover a cornucopia of aesthetic information in its organization. The key term here is "data," a meaningless word which suggests that the relevant level at which to decode the television message is that of the physical structure of light on the screen-but in fact the word has the effect of conflating this level with other levels of information. Gestalt and perceptual psychology mingle with genre theory and a mysticism of the proper name in Murray's postcritical celebration of the medium. For his students, however, television is "worse than junk mail. Television is the death throes of human consciousness, according to them. They're ashamed of their television past. They want to talk about movies." Murray is a postmodernist. His students, wishing to return to the high modernism of cinema, are postpostmodernist.

The smoke alarm went off in the hallway upstairs, either to let us know the battery had just died or because the house was on fire. We finished our lunch in silence.

When the jug-eared computer operator taps into Jack's data profile (his history-but what history? "Where was it located exactly? Some state or federal agency, some insurance company or credit firm or medical clearinghouse?") he finds that "[w]e have a situation": "It's what we call a massive data-base tally." This tally doesn't actually mean anything except that Jack is "the sum total of [his] data." like so many signifying structures in White Noise it offers a profound in 
terpretability but withdraws any precise meaning, or is at best deeply ambivalent. It's nothing but data, raw and unreadable. And what constitutes data is of course not something given, as the word suggests, but a set of constructs, figures whose significance lies not in their inherent structure but in the decision that has been taken to frame them in a certain way. The word embodies all the pathos of an impoverished and institutionalized empiricism. Its faultiness is caught in a joke about the search for contamination in the girls' school; the search is carried out by men in Mylex suits, but "because Mylex is itself a suspect material, the results tended to be ambiguous."

Whereas the sign causes unease, a sense that there is more to be known, the proper name is the site of a magical plenitude. Proper names tend to come in cadenced triads: "The Airport Marriott, the Downtown Travelodge, the Sheraton Inn and Conference Center." "Dacron, Orlon, Lycra Spandex." "Krylon, Rust-Oleum, Red Devil." They appear mysteriously in the midst of the mundane world of novelistic narrative, detached, functionless, unmotivated. At the end of a paragraph on Babette's fear of death, "the emptiness, the sense of cosmic darkness," occurs the single line: “MasterCard, Visa, American Express." The sonorous, Miltonic names lack all epic content, and they are intruded into the text without any marker of a speaking source. In a later episode the sleeping Steffie, speaking in "a language not quite of this world," utters two words

that seemed to have a ritual meaning, part of a verbal spell or ecstatic chant.

Toyota Celica.

A long moment passed before I realized this was the name of an automobile. The truth only amazed me more. The utterance was beautiful and mysterious, gold-shot with looming wonder. It was like the name of an ancient power in the sky, tablet-carved in cuneiform.

Here there is a definite source for the utterance, but in another sense Steffie is not this source: the words are spoken through her, by her unconscious but also, as Jack recognizes, by the unconscious of her culture. Yet for all their commercial banality (the same that echoes 
gloriously through a phrase caught on the radio: "It's the rainbow hologram that gives this credit card a marketing intrigue"), the names remain charged with an opaque significance, so that Jack remarks: "Whatever its source, the utterance struck me with the impact of a moment of splendid transcendence."

The question of the source of enunciation of these proper names remains an interesting one, as there seems to be a definite progression in the novel from an apparently impersonal enunciation to more localized points of origin. In a description of the supermarket, "full of elderly people who look lost among the hedgerows," the words "Dristan Ultra, Dristan Ultra" occur on a separate line but are enclosed within inverted commas, which indicates a diegetic sourceprobably a public address system in the supermarket. The words have the same sort of status as the voices emanating from the television and the radio that punctuate the life of the house. At other times a psychological source seems to be indicated-when the words "leaded, unleaded, super unleaded" intrude into Jack and Babette's desperate lovemaking; or when the spelled out acronyms "Random Access Memory, Acquired Immune Deficiency Syndrome, Mutual Assured Destruction" cross the text as Jack is crossing the slum districts of Iron City. At other times there seem to be verbal associations flowing between the proper names and their textual context: "I watched light climb into the rounded summits of high-altitude clouds. Clorets, Velamints, Freedent." The movement is not just the phonetic one from clouds (perhaps "cloud turrets") to Clorets but is also a circuit between the novel's imagery of sunsets and the poetry of advertising. Another example: Jack experiences "aural torment" as he imagines Babette making love to the mysterious Mr. Gray:

... Then gloom moved in around the gray-sheeted bed, a circle slowly closing.

Panasonic.

Like the syllables of the Proustian name, the last word is multiply motivated. "Pana-" is the circle slowly closing, "sonic" is Jack's aural torment, and there are overdetermined traces of "panoramic" and, of course, television. But as with the name in Proust, the point is the excess of the poetic signifier over its component parts, its transcenden. 
tal character, its plenitude. The poetic word comes from elsewhere, and if it seems to be spoken by a character (like the woman passing on the street who says "a decongestant, an antihistamine, a cough suppressant, a pain reliever"), this is nevertheless only a proximate source, a relay. The proper name is its own absolute origin.

At lunchtime Wilder sits surrounded by "open cartons, crumpled tinfoil, shiny bags of potato chips, bowls of pasty substances covered with plastic wrap, flip-top rings and twist ties, individually wrapped slices of orange cheese." Meals in this house lack the monumental solidity of the meals in Buddenbrooks or even in the James Bond novels; they are depthless, physically insubstantial. At times the staple junk food is opposed to the "real" (but never achieved) lunch of yogurt and wheat germ, but the truth of the matter is that eating has entirely to do with surfaces. Even chewing gum is described in terms of its wrappings.

The supermarket is the privileged place for a phenomenology of surfaces. Murray is a devotee of generic brands, and he takes their "flavorless packaging" to be the sign of a new austerity, a new "spiritual consensus." The packaging on supermarket goods, he says, "is the last avant-garde. Bold new forms. The power to shock." But even unprocessed and unpackaged foods take on the form of packaging: "There were six kinds of apples, there were exotic melons in several pastels. Everything seemed to be in season, sprayed, burnished, bright." And later: "The fruit was gleaming and wet, hard-edged. There was a self-conscious quality about it. It looked carefully observed, like four-color fruit in a guide to photography. We veered right at the plastic jugs of spring water." The kitchen, too, is a place of containers and packagings - the freezer, for example, where "a strange crackling sound came off the plastic food wrap, the snug covering for half eaten things, the Ziploc sacks of liver and ribs, all gleaming with sleety crystals."

But the force of this is not a sentimental regret for a lost world of depths, a nostalgic opposition of surface to substance. There is a depth to be found in this world (this house, this novel), but it is not a fullness of being; rather, it's the other end of the packaging process, 
a sort of final interiority of the wrapping. Jack comes across it when he searches through the trash bag of the compactor:

An oozing cube of semi-mangled cans, clothes hangers, animal bones and other refuse. The bottles were broken, the cartons flat. Product colors were undiminished in brightness and intensity. Fats, juices and heavy sludges seeped through layers of pressed vegetable matter. I felt like an archaeologist about to sift through a finding of tool fragments and assorted cave trash.

This is the heart of domesticity:

I found a banana skin with a tampon inside. Was this the dark underside of consumer consciousness? I came across a horrible clotted mass of hair, soap, ear swabs, crushed roaches, flip-top rings, sterile pads smeared with pus and bacon fat, strands of frayed dental floss, fragments of ballpoint refills, toothpicks still displaying bits of impaled food. There was a pair of shredded undershorts with lipstick markings, perhaps a memento of the Grayview Motel.

The list is of an accretion of wastes that have come full circle from the supermarket but which still retain the formal structure (and even the "undiminished colors") of the presentation of surfaces. At the heart of this inside is nothing more than a compacted mass of outsides.

White Noise is a domestic novel, continuously concerned with the secret life of the house-with the closet doors that open by themselves, with the chirping of the radiator, with the sounds of the sink and the washing machine and the compactor, with the jeans tumbling in the dryer. The narrator writes of the "numerous and deep" levels of data in the kitchen, and speaks of the kitchen and the bedroom as "the major chambers around here, the power haunts, the sources." But the center of the life of the house is the voice of the television. This is what it says:

Let's sit half-lotus and think about our spines. 
If it breaks easily into pieces, it is called shale. When wet, it smells like clay.

Until Florida surgeons attached an artificial flipper.

(In a British voice): There are forms of vertigo that do not include spinning.

And other trends that could dramatically impact your portfolio.

This creature has developed a complicated stomach in keeping with its leafy diet.

Now we will put the little feelers on the butterfly.

Meanwhile here is a quick and attractive lemon garnish suitable for any sea food.

Now watch this. Joanie is trying to snap Ralph's patella with a bushido stun kick. She makes contact, he crumples, she runs.

They're not booing - they're saying, "Bruce, Bruce."

Television is about everything. It is about the ordinary, the banal, information for living our lives. It is rarely the voice of apocalypse. 


\section{University Library}

\section{- M M I N E R VA A gateway to Melbourne's research publications}

Minerva Access is the Institutional Repository of The University of Melbourne

Author/s:

Frow, John A.

Title:

The last things before the last: notes on White Noise

Date:

1990

Citation:

Frow, J. A. (1990). The last things before the last: notes on White Noise. South Atlantic Quarterly, 89(2), 413-430.

Publication Status:

Published

Persistent Link:

http://hdl.handle.net/11343/34141 